\title{
TRANSVERSUS ABDOMINIS PLANE BLOCK FOR POST-CAESAREAN PAIN. A RETROSPECTIVE STUDY
}

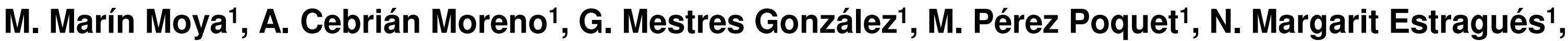 \\ S. Gasca Pera', À. Jaen Manzanera², C. Pérez Torrentó1. \\ ${ }^{1}$ Hospital Universitari Mutua Terrassa, Anaesthesiology, Terrassa, Spain. \\ ${ }^{2}$ Research Foundation Mutua Terrassa, Research Unit, Terrassa, Spain
}

\section{BACKGROUND AND AIMS}

Ultrasound-guided transversus abdominis plane (TAP) block is a method for providing analgesia after caesarean delivery.

The aim of our study is to describe the pain relief in patients in which this regional technique is added to conventional analgesia.

\section{METHODS}

After the approval from the ethical committee we included in this retrospective study 122 pregnant women who had an elective caesarean section (CS) between August 2017 and March 2018 in our centre. Patients were placed in two groups: T or TAP block group $(n=85)$ and $C$ or control group $(n=37)$. The exclusion criteria were: being under 18 years old, chronic treatment with opioids, not carrying specific protocolized postoperative analgesia and general anesthesia. The primary outcome was pain, evaluated with the visual analogue scale (VAS) from 0 to 10. Pain was considered when VAS was greater than 3 . It was registered at post-anaesthesia care unit (PACU) and at 4, 8, 12 hours post CS. The number of intravenous analgesia rescues in the first $24 \mathrm{~h}$ after CS were also reported.

\section{RESULTS (Fig. 1)}

Pain scores at PACU, 4h, 8h and 12h were not statistically significant between both groups. Observed pain in PACU was $17,7 \%$ (15/85) in T group vs $32.4 \%(12 / 37)$ in C group $(p=0.07$ ). Median (interquartile range $25 \%-75 \%$ ) number of analgesia request doses received between 0 and $24 \mathrm{~h}$ was lower in T group: 1 (0-2) versus $C$ group: 2 (1-2).

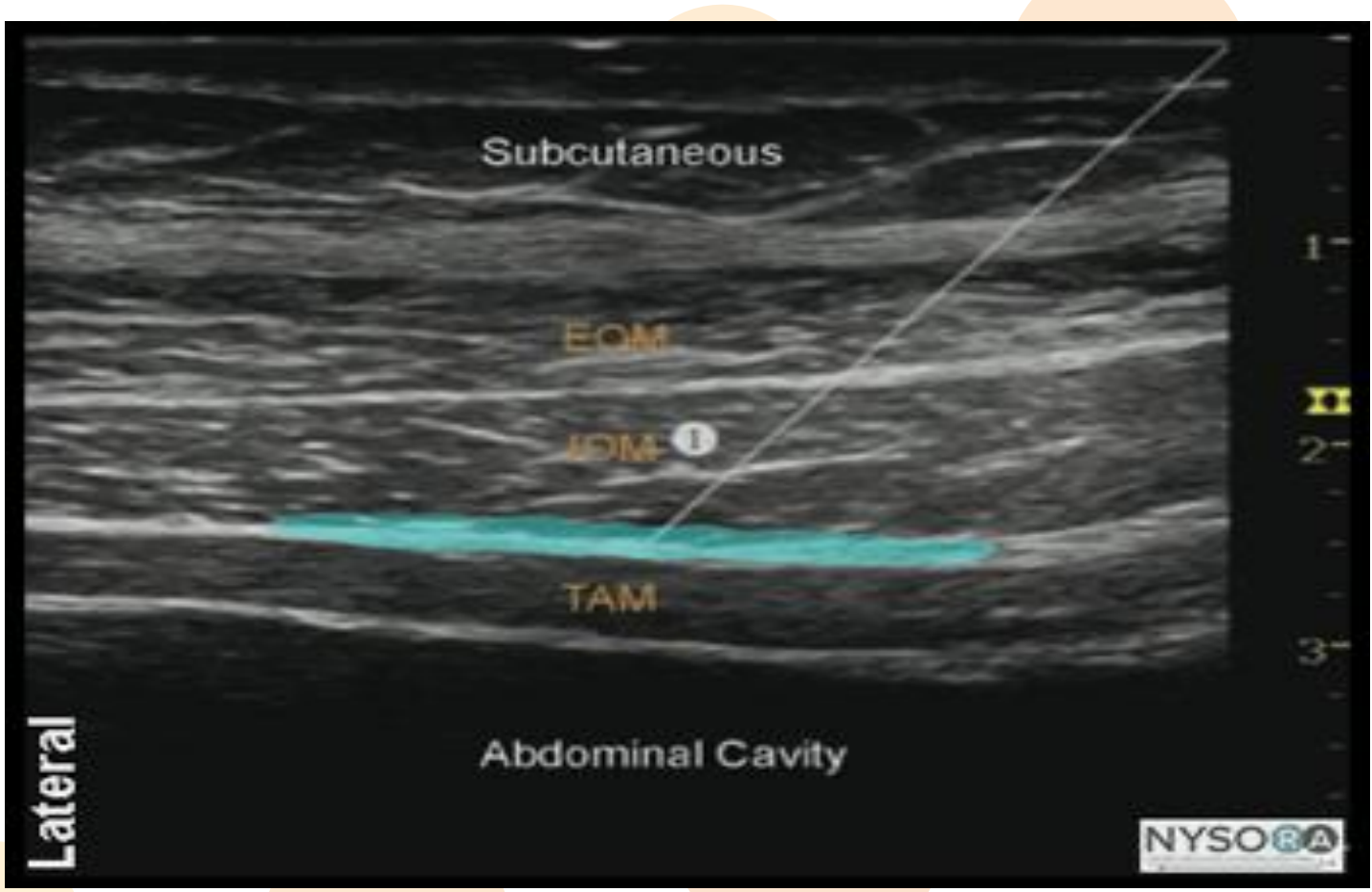

EOM: external oblique muscle, IOM: internal oblique muscle, TAM: transverse muscle

References

NYSORA The New York School of Regional Anesthesia. (2018). Available at: https://www.nysora.com/truncal-and-cutaneousblocks [Accessed 4 Sep. 2018].

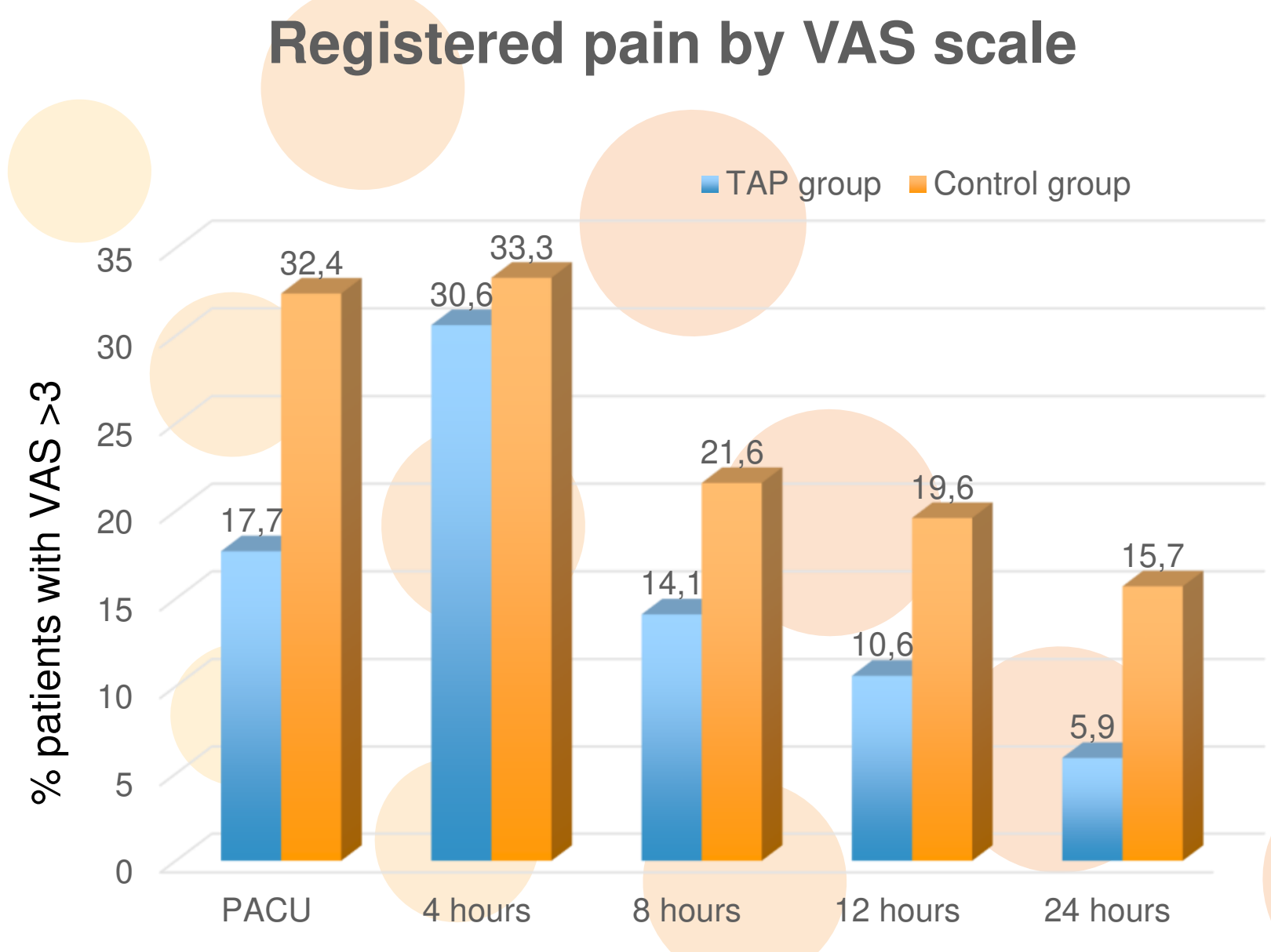

Figure 1. Percentage of registered pain by VAS scale (VAS $>3$ ) at different times after CS comparison between TAP block and control group $(p>0,05)$

\section{CONCLUSIONS}

We conclude that performing a TAP block in CS decreases the need of intravenous rescues the first 24h. A tendency (close to significance) to the reduction of postoperative pain was observed. It would be necessary more studies with a prospective clinical trial design in order to achieve a better assessment of its efficacy.

1. Ripollés J, Mezquita SM, Abad A, Calvo J. Analgesic efficacy of the ultrasound-guided blockade of the transversus abdominis plane - a systematic review. Brazilian J Anesthesiol (English Ed. 2015;65:255-80.

2. Analgesic efficacy of the ultrasound-guided blockade of the transversus abdominis plane - a systematic review. Brazilian J Anesthesiol (English Ed. Elsevier; 2015;65:255-80.

3. F.W. Abdallah et col. duration of analgesic effectiveness after the posterior and lateral transversus abdominis plane block techniques for transverse lowe abdominal incisions: a meta-analysis. British Journal of Anesthesia. 